\title{
CONGRESSO LATINO-AMERICANO DE VAREJO: RETROSPECTIVA DE CINCO ANOS
}

Valter Afonso Vieira valterafonsovieira@yahoo.com

Professor do PPA/UEM

Heitor Takashi Kato heitorkato.pucpr@gmail.com

Professor da PUC-PR

Eliane Pereira Zamith Brito eliane.brito@fgv.br

Professora da FGV-EAESP

Lelis Balestrin Espartel lbespartel@pucrs.br

Professor do PPGAd/ PUC-RS

Iniciado em 2008, o Congresso Latino-Americano de Varejo (CLAV), promovido pelo GVCev da EAESP nas dependências da Fundação Getulio Vargas, tem crescido na interlocução dos pesquisadores, na quantidade de trabalhos e na qualidade dos palestrantes nacionais e internacionais, ganhando destaque no cenário do estudo do varejo. Desde o primeiro encontro, esse evento tem conseguido reunir estudantes, pesquisadores e demais profissionais no que tange às distintas vertentes do segmento varejista, tanto do Brasil quanto do exterior, como Estados Unidos, Argentina e Áustria, entre outros.

Ao longo dos últimos cinco anos, idade do evento, o varejo vem sofrendo mudanças expressivas no cenário internacional, o que acaba refletindo nas discussões dos profissionais, dos pesquisadores e da academia nacional. Uma das mutações mais expressivas foi a grande crise provocada pelo estouro da "bolha imobiliária" nos Estados Unidos da América, com o consequente enfraquecimento, em alguns casos até falência, de muitas instituições do setor bancário americano e europeu. Contrariamente, o segmento imobiliário brasileiro viu-se diante de um crescimento, desde 2008, eloquente e positivo. De fato, o Brasil galgou números positivos em sua economia.

No ano de 2011, o Produto Interno Bruto (PIB) do Brasil cresceu 2,7\% sobre o ano anterior, 2010 , totalizando $\mathrm{R} \$ 4,143$ trilhões ou US\$ 2,367 trilhões (dados divulgados pelo IBGE em 06 de março de 2012). Esse crescimento, de acordo com o IBGE, é resultado do aumento de $4,3 \%$ nos impostos e $2,5 \%$ no valor adicionado.
No contexto de país emergente, devemos esperar um interesse renovado pelo varejo, pois outros mercados, outrora atrativos, tornaram-se menos interessantes neste período de Europa com as contas internas combalidas e contração nos gastos públicos, por conta de políticas de austeridade fiscal. Nesse sentido, o CLAV, refletindo o ambiente acadêmico e de negócios do Brasil e da América Latina, pode proporcionar aos participantes do evento um melhor entendimento do varejo nos mercados emergentes.

De fato, o CLAV possui uma característica diferenciada em termos de congresso, dada a delimitação no formato do evento. O formato mais enxuto e focado proporciona um período mais condensado à discussão dos artigos aprovados, nos trabalhos de 
qualificação de doutoramento, nas palestras de profissionais nacionais convidados e nos seminários dos painelistas internacionais atraídos. Dessa forma, o formato do evento não fica cansativo e proporciona um andamento mais equilibrado entre a altercação da produção científica e a discussão dos tópicos contemplados pelos palestrantes. Fazendo uma retrospectiva nesses cinco anos de evento, notar-se-á um crescimento expressivo.

$\mathrm{O} 1^{\circ}$ CLAV aconteceu nos dias 8 e 9 de outubro de 2008 e teve como tema "Varejo em mercados emergentes: desafios e perspectivas". Na ocasião, foram apresentados e discutidos 15 artigos, sendo 11 deles acadêmicos e 4 chamados "artigos de negócios". Tomando-se os temas que hoje formam as trilhas acadêmicas do CLAV, e considerando-se apenas os artigos acadêmicos, a trilha "comportamento do consumidor" foi a que mais contribuiu para o evento. Também foram apresentados artigos para as trilhas "estratégias varejistas", "responsabilidade social e sustentabilidade", "relacionamento, parcerias e supply chain" e "eficiência e tecnologia". Nesse evento, os palestrantes foram Robert Lusch, da University of Arizona, e Barton Weitz, da University of Florida, consagrados pesquisadores norte-americanos, além do professor Juracy Parente.

O $2^{\circ}$ CLAV ocorreu nos dias 22 e 23 de outubro de 2009, com o tema "Estratégias em cenários turbulentos: otimizando valor e buscando eficiência”. O evento contou, mais uma vez, com renomados pesquisadores. O professor Wagner Kamakura, da Duke University (USA), falou sobre "Como elaborar artigos científicos em varejo", enquanto o professor Gerard
Tellis, da University of Southern California, proferiu palestra intitulada "Innovation of firms across nations". Além disso, o evento contou com um painel que teve como participantes presidentes de empresas varejistas. Os empresários José Galló (Lojas Renner), Fernando de Castro (TelhaNorte/ Saint-Gobain) e Cláudio Roberto Ely (Drogasil) foram provocados com o tema "Surfando em tempos turbulentos". Foram apresentados 25 artigos científicos de pesquisadores de diversas instituições, sendo que as trilhas acadêmicas "comportamento do consumidor" e "estratégias varejistas" dominaram os debates.

O $3^{\circ}$ CLAV, ocorrido nos dias 21 e 22 de outubro de 2010, teve como tema "Competitividade no varejo: teoria e relevância prática". O evento teve 35 artigos acadêmicos aprovados para apresentação e discussão. De maneira geral, os artigos deram ênfase a estudos sobre comportamento do consumidor, estratégias varejistas e branding. Como palestrantes, o evento contou com o professor James Brown, da West Virginia University, que deu indicativos para responder à pergunta "How relevant is your research?", usando toda sua experiência como coeditor do Journal of Retailing, hoje o principal periódico científico de varejo no mundo. Já o professor Edward Fox, da Southern Methodist University (USA), falou sobre "Competitiveness in retailing". Além deles, os executivos Alejandro Padron (IBM), Fabio Silvestri (Accenture) e Ricardo Neves (PWC) discutiram o tema "Concentração e concorrência no setor varejista".

$\mathrm{O} 4^{\circ}$ CLAV aconteceu nos dias 27 e 28 de outubro de 2011, e teve como tema "Redes sociais e varejo: como as novas mídias influenciam o setor". Foram apresentados 45 artigos durante o evento, sendo as trilhas acadêmicas de maior destaque "comportamento do consumidor", "atmosfera de loja" e "decisão de compra no varejo". Entre os palestrantes internacionais, o evento iniciou com o professor Guillermo D’Andrea, da IAE Business School (Argentina), falando sobre "Challenges to emerging retailing". A seguir, Chrysanthos Dellarocas, da Boston University, palestrou sobre a "Criação e difusão de informação pelas mídias sociais e o uso dessa informação pela empresa varejista". Por fim, a professora Hope Jensen Schau, da University of Arizona, falou sobre "Como as mídias sociais afetam o comportamento do consumidor". Como palestrantes nacionais e executivos de empresas, estiveram presentes Mauricio Mota, Barbara Rodrigues, Gerson Schitt, Edney Souza, Thiago Abreu, Marcelo Coutinho, Francisco Saraiva e Alexandre Kavinski.

O tema do CLAV em 2012 é "Varejo: desafios e oportunidades em mercados emergentes". O palestrante convidado é o professor Shankar Ganesan, da University of Arizona, e atual editor do Jounal of Retailing, com o tema "Compartilhamento de conhecimento entre fornecedores em ambientes de Competition". Os 50 trabalhos a serem apresentados mostram uma predominância de artigos com foco no ambiente da loja, varejo on-line, branding e comportamento do consumidor. Nesta quinta edição do evento, o fator de destaque é o aumento no número de artigos em inglês, atingindo o pico do CLAV, com seis trabalhos, contra dois artigos, em média, nos outros eventos anteriores. Esses seis artigos (quatro de autores do exterior) 
mostram a internacionalização e a vontade de contribuir e de participar de um evento que discutirá as características do varejo nos países emergentes.

Verifica-se que o CLAV, nesta trajetória de cinco anos, já reflete uma solidez e interesse cada vez maiores dos países latino-americanos em conhecer mais o varejo internacional e nacional. Nesse sentido, o varejo brasileiro está numa posição de destaque para ser o foco de atenção do acadêmico e do executivo interessado nesse mercado. Dessa forma, o CLAV deve ganhar um interesse da comunidade acadêmica cada vez maior e se consolidar como um fórum de discussão do varejo brasileiro e global.

Essa consolidação se verifica pela qualidade dos trabalhos apresentados no ano passado, dos quais os melhores são apresentados nesta edição especial da $R A E$.

\section{O QUE SE PODE ESPERAR DA PESQUISA BRASILEIRA EM VAREJO PARA OS PRÓXIMOS ANOS?}

O incremento da quantidade de pesquisas em varejo e pesquisadores interessados no tópico merece atenção dos envolvidos. Além das inúmeras possibilidades de temas de relevância para a academia e para a comunidade empresarial, propostos por Brito, Vieira e Espartel (2011), a pesquisa brasileira no varejo deve ser orientada com base em uma série de questionamentos, a fim de que o aumento da quantidade seja acompanhado pela qualidade do que se produz.
Nesse sentido, vale destacar:

- de maneira geral, qual a relevância da pesquisa em varejo feita hoje no Brasil?

o que é e o que não é pesquisa no varejo? Quando a pesquisa se caracteriza como relevante ao varejo ou quando a pesquisa tem o varejo como lócus? Por exemplo, estudar o comportamento do consumidor no varejo é pesquisa em comportamento do consumidor ou pesquisa em varejo? Para aprofundar essas questões, sugerimos a leitura de reflexão feita por Macinnis e Folkes (2009) e o recente editorial do Journal of Retailing (GANESAN, 2012); a nossa pesquisa segue o rigor exigido de uma pesquisa científica? Nossos pesquisadores têm capacidade teórica, metodológica e analítica de produzir conhecimento? De acordo com Deighton (2005), um bom artigo passa pelo domínio de teoria (os resultados estão de acordo com o paradigma teórico), domínio de procedimentos (os métodos aplicados inspiram confiança nos achados) e domínio de resultados (são singulares e iluminam o entendimento do fenômeno analisado). Não há dúvida de que existem outros atores responsáveis pela qualidade da publicação brasileira, com destaque especial para revisores e editores de periódicos, e avaliadores e organizadores de eventos científicos. A discussão do papel de cada um é clara no documento Boas Práticas da Publicação Científica, produzido pela Associação Nacional de Pós-Graduação e Pesquisa em Administração;

- além de uma eventual baixa qualidade da produção acadêmica, como lidar com a má-fé na pesquisa? Infelizmente, de acordo com Luce, McGill e Peracchio (2012), a discussão acadêmica mudou: em vez de tentarmos entender como novas descobertas científicas contribuem para o avanço teórico do campo de estudo, o que se debate é se tais descobertas são confiáveis. Os recentes escândalos envolvendo plágio e falsificação de dados servem como alerta;

- há espaço para um periódico brasileiro em varejo? As alterações no sistema de avaliação da CAPES na última década forçaram uma migração da publicação de eventos para periódicos, o que, aliado ao aumento do número de PPGs e de pesquisadores, exige maior quantidade de periódicos para submissão;

- é possível fazer pesquisa em varejo fugindo da abordagem hipotético-dedutiva? Recente artigo de Alba (2012) estimula os pesquisadores a prestarem mais atenção no "o que" antes do "como", do "quando" e do "por que". O que o autor sugere é que existem muitos fenômenos (encontrados no varejo, inclusive) que não são observados empiricamente porque não há (ainda) uma teoria formal que o sustente. Park (2012) afirma que há espaço para dois tipos de pesquisa: a que produz conhecimento interessante, mas incompleto (chamada de cute research), e a que gera conhecimento útil e completo (denominada beautiful research). E no Brasil, o que acontece?

seguindo a mesma linha de 
provocação de Baumgartner (2010), quais tipos de artigos seriam mais influentes na pesquisa em varejo? Como um pesquisador obtém impacto ou destaque na área? De acordo com Brown e Dant (2008), existem algumas formas de aumentar a contribuição de um artigo no varejo, quais sejam: (1) prover novos conhecimentos, (2) aprofundar o entendimento do conhecimento existente, (3) descobrir resultados surpreendentes e (4) abordar problemas gerenciais interessantes.

Mesmo que muitos dos questionamentos aqui apresentados não tenham uma resposta fácil ou definitiva, nosso objetivo é provocar a reflexão e o debate entre acadêmicos que tenham interesse em conduzir suas pesquisas em varejo, sem nunca deixar de lado os interesses da comunidade empresarial. Não há mais espaço para a dicotomia teoria-prática. É recomendável que os pesquisadores acompanhem a realidade do mercado, e que os executivos vejam na academia um suporte para o melhor entendimento desse mercado. Essa relação, com toda a sua riqueza, deve ser valorizada no contexto do varejo. E o CLAV tem proporcionado isso com muita propriedade nestes últimos cinco anos.

\section{FÓRUM VAREJO}

Em 2011, foi lançado o primeiro Fórum de Varejo na RAE-Revista de Administração de Empresas, contendo trabalhos apresentados no congresso. Neste ano, a parceria se repete. Foram 15 os trabalhos pré-selecionados e convidados a participar do fórum. Os artigos foram, então, submetidos à avaliação double blind por um grupo de avaliadores ad hoc com experiência em pesquisas em varejo. Ao final do processo de avaliação, sete artigos foram aprovados, sendo brevemente apresentados a seguir.

No primeiro artigo, Carlos Alberto Alves, Luis Fernando Varotto e Marcelo Neves Gonçalves apresentam "Objetivos e métodos de preço no varejo: estudo na zona sul de São Paulo", em que avaliam se há sintonia entre objetivos de preço e métodos de precificação no varejo. Com base em uma survey realizada junto a 300 centros comerciais de bairro, da zona sul da cidade de São Paulo, a pesquisa indicou que as empresas dão ênfase maior à realização de vendas e lucros, seguida pelo desenvolvimento de mercado. Além disso, parece dar-se menor importância a métodos de orientação ao cliente.

No artigo chamado "Brasileiro gosta de 'muvuca'? Impacto da densidade humana no comportamento de compra", Marcelo Moll Brandão e Juracy Parente discutem o conceito de crowding, com base na densidade humana (ou "muvuca", conforme o artigo) em ambientes varejistas. Por meio de estudos experimentais, os autores testaram diferentes respostas dos consumidores, e os resultados mostram que a sensibilidade dos consumidores às variações de densidade humana é baixa entre os níveis baixo e médio, mas a reação negativa aumenta quando a densidade humana se eleva do nível médio para o alto.

A seguir, o artigo intitulado "Efeito dos fatores de merchandising nas vendas do varejo", de autoria de Fabrício Rodrigues Feijó e Delane Botelho, traz à tona a relação do merchandising no ponto de venda com os resultados em termos de vendas no varejo. Com base em um desenho de pesquisa quasi-experimental aplicado a uma rede de lojas de calçados, os autores mostram que, por causa da ambientação das lojas do grupo de controle de acordo com o modelo de merchandising, houve um incremento significativo do desempenho, indicando que os fatores de merchandising podem influenciar o consumidor no ambiente de loja.

O quarto artigo, intitulado "Trade marketing no setor de lojas de conveniência", é de autoria de Victor Manoel Cunha de Almeida, Leonardo Siano Penna, Gilberto Figueira da Silva e Flávia D'Albergaria Freitas. O texto busca descrever as motivações para a adoção do trade marketing no setor de lojas de conveniência. Baseado no estudo de casos múltiplos, o artigo aponta para uma relação tripartite, com a participação de fabricante, franqueador e franqueado, em que as ações de trade marketing são negociadas com o franqueador e operacionalizadas com o franqueado.

$\mathrm{Na}$ sequência, aparece o artigo denominado "Influence of discount price annoucements on consumer's behavioral", de autoria de Giuliana Isabella, Alexandre Ierulo Pozzani, Vinicios Anlee Chen e Murillo Buissa Perfi Gomes. Nele, os autores discutem o processo de decisão do consumidor considerando diferentes formas de apresentação de ofertas de desconto, tendo como suporte teórico a teoria da perspectiva e a contabilidade mental. Com base em dois estudos experimentais, os 
resultados indicam respostas diferentes dos indivíduos a mudanças na estrutura da oferta.

O penúltimo artigo, chamado "Shopping for apparel: how can kiosk systems help?", tem como autoras Monika Koller e Andrea Königsecker. O artigo, de caráter qualitativo, investiga a avaliação dos clientes com respeito aos quiosques dentro das lojas como apoio à decisão de compra. Os resultados indicam que os quiosques têm avaliação positiva dos consumidores apenas quando são vistos como uma fonte alternativa de informações na loja.

Por fim, o último artigo do fórum, "Sponsoring, brand value and social media", de autoria de Alexander Zauner, Monika Koller e Matthias Fink, foi premiado como melhor trabalho do $4^{\circ}$ CLAV. Nele, os autores investigam as implicações dos patrocínios nas mídias sociais, especificamente avaliando se a imagem da marca e a credibilidade do endosso influenciam o valor da marca da empresa investidora. A pesquisa, realizada via Facebook, traz interessantes contribuições para o entendimento da eficiência do endosso de celebridades nas mídias sociais.

\section{REFERÊNCIAS}

ALBA, J. W. In defense of bumbling. Journal of Consumer Research, v. 38, n. 6, p. 981-987, 2012.

BAUMGARTNER; H. Bibliometric Reflections on the history of consumer research. Journal of Consumer Psychology, v. 20, n. 3, p. 233-238, 2010.
BRITO, E. P. Z; VIEIRA, V. A; ESPARTEL, L. B. A pesquisa na área do varejo: reflexões e provocações. RAE-Revista de Administração de Empresas, v. 51, n. 6, p. 522-527, 2011.

BROWN, J. R; DANT, R. P. On what makes a significant contribution to the retailing literature. Journal of Retailing, v. 84, n. 2, p. 131-135, 2008.

DEIGHTON, J. From the editor-elect. Journal of Consumer Research, v. 32, n. 1, p. 5-9, 2005.

GANESAN, S. From the editor Journal of Retailing in the global marketplace (Editorial). Journal of Retailing, v. 88, n. 2, p. 189-190, 2012.

IBGE (INSTITUTO BRASILEIRO DE GEOGRAFIA E ESTATÍsTICA). Disponível em: http://www.ibge. gov.br/home/presidencia/noticias/ noticia_visualiza.php?id_noticia=2093. Acesso em 03.10.2012.

LUCE, M. F; MCGILL, A; PERACCHIO, L. Promoting an environment of scientific integrity: individual and community responsabilities. Journal of Consumer Research, v. 39, n. 3, p. 3-5, 2012.

MacINNIS, D. J; FOLKES, V. S. The disciplinary status of consumer behavior: a sociology of science perspective on key controversies. Journal of Consumer Research, v. 36, n. 6, p. 899-914, 2010.

PARK, C. W. Two types of attractive research: cute research and beautiful research (Editorial note). Journal of Consumer Psychology, v. 22, n. 3, p. 299-302, 2012. 